Original Research Paper

\title{
Budidaya Tanaman Hortikultura Menggunakan Metode Vertikultur dan Vertical Garden Sebagai Alternatif Usaha Pemanfaatan Lahan Masyarakat Kelurahan Sekarteja
}

\author{
M. Rifaldi Rahman ${ }^{1}$, A. Defi Yulita Pratiwi ${ }^{1}$, Aina UI Mardiati ${ }^{1}$, Damarizki Ideatami ${ }^{1}$, Laili Ruhyani \\ Udlhi $^{1}$, Lalu Aulia Rahman Hakim ${ }^{1}$, Patika Azmia Putri ${ }^{1}$, Puspita Ariyaningsih ${ }^{1}$, Siti Aisah Purnamasari ${ }^{1}$, \\ Yulistiana Ummami ${ }^{1}$, Immy Suci Rohyani ${ }^{2}$ \\ ${ }^{1}$ Universitas Mataram, Mataram, Indonesia.
}

DOI: https://doi.org/10.29303/jpmpi.v4i2.690

Sitasi: Rahman, M. R., Pratiwi, A. D. Y., Mardiati, A. U., Ideatami, D., Udlhi, L. R., Hakim, L. A. R., Putri, P. A., Ariyaningsih, P., Purnamasari, A., Ummami, Y., \& Rohyani, I. S. (2021). Optimalisasi Pemanfaatan Lahan Pekarangan Sebagai Penyangga Ketahanan Pangan Keluarga. Jurnal Pengabdian Magister Pendidikan IPA, 4(2)

\section{Article history}

Received: 03 Februari 2021

Revised: 08 Maret 2021

Accepted: 10 April 2021

*Corresponding Author:

M. Rifaldi Rahman,

Universitas Mataram, Mataram, Indonesia;

Email: aldi6653@gmail.com

\begin{abstract}
Rumah Pangan Lestari (RPL) adalah upaya pemenuhan kebutuhan pangan dan gizi dapat ditingkatkan diantaranya melalui pemanfaatan lahan pekarangan rumah tangga yang berkualitas dan beragam. Pelaksanaan program kegiatan Tim Pengabdian program RPL ini menggunakan teknik Vertical garden dan vertikultur. Tujuan dari kegiatan ini adalah untuk meningkatkan kesadaran keluarga dan masyarakat dalam pemanfaatan lahan pekarangan untuk budidaya tanaman pangan seperti sayuran, tanaman obat, serta pemanfaatan limbah plastik rumah tangga. Metode yang digunakan dalam pelaksanaan kawasan rumah pangan lestari (RPL) ini meliputi sosialisasi kegiatan dan perencanaan diskusi ataupun ceramah dan dengan melakukan demonstrasi kegiatan secara langsung kepada masyarakat. Teknik pengumpulan data yang digunakan adalah observasi dan wawancara. Hasil yang diperoleh dari kegiatan Rumah Pangan Lestari ini berupa kangkung, sawi pakcoy, sawi pagoda, selada merah dan selada hijau, cabai, bayam, tomat, timun, singkong, daun mint, dan terong.
\end{abstract}

Keywords: Rumah Pangan Lestari; Vertical Garden; Vertikultur.

\section{Pendahuluan}

Kelurahan Sekarteja merupakan salah satu Kelurahan di Kecamatan Selong, Kabupaten Lombok Timur. Dalam memperoleh bahan pangan masyarakat, Kelurahan Sekarteja banyak melakukan kegiatan jual beli di pasar dibandingkan bahan pangan yang dikelola atau dibudidayakan sendiri. Ditengah pandemi seperti sekarang ini kebutuhan pangan menjadi sangat tinggi yang diikuti oleh melonjakknya harga bahan pangan. Sehingga kebutuhan masyarakat akan pangan semakin meningkat. Di wilayah Sekarteja masyarakat kekurangan lahan untuk bercocok tanaman. Kurangnya kesadaran masyarakat dalam memanfaatkan lahan pekarangan akan berakibat bagi ketersediaan pangan yang dibutuhkan oleh masyarakat itu sendiri. Mengingat kelurahan Sekarteja berupa komplek perumahan dan penduduk yang cukup padat, lahan pekarangan dapat dijadikan sebagai salah satu tempat untuk bercocok tanam. Oleh karena itu, perlunya meningkatkan kesadaran keluarga dan masyarakat dalam pemanfaatan lahan pekarangan untuk budidaya tanaman pangan seperti sayuran, tanaman obat keluarga, serta pemanfaatan limbah plastik rumah tangga perlunya meningkatkan kesadaran masyarakat dalam memanfaatkan lahan-lahan pekarangan yang mereka punya untuk melakukan kegiatan bercocok tanam. Kegiatan bercocok tanam 
dengan memanfaatkan lahan pekarangan rumah dapat dilakukan dengan beberapa metode seperti vertikultur dan vertical garden. Hortikultura berasal dari bahasa latin yaitu dari kata hortus artinya kebun, dan culture artinya bercocok tanam. Secara umum holtikultira adalah segala kegiatan bercocok tanam seperti sayur-sayuan, buah-buahan, ataupun tanaman hias dimana lahan (kebun atau pekarangan rumah) sebagai tempatnya. Tanaman pada hortikultura berguna sebagai sumber daya untuk dikonsumsi, tapi ada juga untuk hal keindahan. Biasanya hasil yang diperoleh dari budidaya secara hortikultura selalu upayakan lebih tinggi daripada cara budidaya tanaman lainnya, karena hortikultura menggunakan lahan atau area yang lebih luas untuk bercocok tanam. Saat ini tanaman hortikultura menjadi tanaman budidaya di kebun dengan skala yang bersar, tapi bisa juga tanaman hortikultura dibudidayakan diarea bersekala kecil misalnya di pekarangan rumah sehingga tanamannya dapat memberi manfaat secara langsung kepada yang membudidayakan.

Vertical garden juga sering disebut dengan vertical landscape yang merupakan hasil kreasi inovatif untuk menumbuhkan tanaman dengan memakai sekam bakar atau cocopeat sebagai media pertumbuhan, dengan keberhasilan menemukan sistem pertumbuhan tersebut menyebabkan berkurangnya beban yang harus ditopang pada sebuah dinding sehingga memudahkan dalam penataan desain taman vertikal dalam skala dinding yang luas serta jalan keluar bagi pembuatan taman pada lokasi yang terbatas ketersedian lahannya. Vertical garden dapat diaplikasikan di berbagai bangunan (outdoor maupun indoor), pagar, carport, serta dinding-dinding pembatas lainnya, sehingga terlihat lebih indah dan tidak monoton berupa dinding yang keras, tapi lebih terkesan alami, bahkan dapat menyerupai lukisan yang sangat artistik (Sari, 2013).

Vertikultur merupakan teknik bercocok tanam dilahan yang sempit dengan memanfaatkan bidang vertikal sebagai tempat bercocok tanam yang dilakukan secara bertingkat untuk memanfaatkan lahan yang sempit secara optimal. Struktur dasar yang digunakan cukup mudah dengan bahan sehingga dapat diterapkan di rumahrumah (Sihombing, et al., 2013). Tujuan vertikultur adalah untuk memanfaatkan lahan yang sempit secara optimal. Sistem bertanam secara vertikultur sekilas memang terlihat rumit, tetapi sebenarnya sangat mudah dilakukan. Tingkat kesulitan bertanam secara vertikultur tergantung kepada model dan system tambahan yang dipergunakan. Dalam model sederhana, struktur dasar yang digunakan mudah diikuti dan bahan pembuatannya mudah ditemukan, sehingga dapat diterapkan di rumah- rumah oleh ibu-ibu rumah tangga (Desiliyarni, dkk., 2003).

Berdasarkan hal tersebut, untuk memanfaatkan potensi lokal yang ada di lingkungan Kelurahan Sekarteja dengan memanfaatkan lahan kosong melalui program KRPL yaitu "Budidaya Tanaman Hortikultura Menggunakan Metode Vertikultur dan Vertical garden Sebagai Alternatif Usaha Pemanfaatan Lahan Masyarakat Kelurahan Sekarteja" diharapkan mampu mendukung upaya pembangunan desa dengan mengembangkan potensi lokal desa yang ada di lingkungan Sekarteja.

\section{Metode}

Pelaksanaan Tim Pengabdian RPL ini menggunakan teknik penanaman vertikultur dan Vertical garden sebagai budidaya tanaman hortikultura. Ditujukan untuk meningkatkan pengetahuan, skill (keterampilan) masyarakat dalam mengoptimaliasi lahan pekarangan rumah dengan teknik vertikultur dan vertical garden. Peningkatan kemampuan keterampilan masyarakat Sekarteja dalam pemanfaatan teknologi vertikultur dan vertical garden dilakukan dengan memperlihatkan bagaimana proses pemanfaatan lahan kosong kepada masyarakat setempat secara langsung. Kegiatan Tim Pengabdian ini dilakukan mulai dari tanggal 11 Januari hingga 24 Februari dengan jam kerja selama 6 jam atau lebih perharinya.

Sosialisasi ini dilakukan pada warga dengan perwakilan agar mengurangi kerumunan untuk metapkan protokol kesehan yang berlaku. Sosialisasi ini dilakukan di lokasi KRPL yang dihadiri oleh ketua PKK, remaja masjid, dan juga beberapa masyarakat lingkungan BTN RSS mengenai program rumah pangan lestari melalui teknik vertikultur dan vertical garden didukung dengan pembagian secara langsung hasil tanaman yang dihasilkan. Setelah melakukan sosialisasi, dilakukan pembagian bibit kepada masyarakat dan yang kami utamakan anak-anak, dengan tujuan 
mereka menjadi lebih tertarik dengan sayuran untuk mengkonsumsinya. Hal ini dilakukan dengan memberikan pelatihan kepada masyarakat dengan mendampingi saat melakukan penanaman secara langsung menggunakan teknik vertikultur dan vertical garden. Teknik pengumpulan data yang digunakan adalah observasi dan wawancara.

\section{Hasil dan Pembahasan}

Pelaksanaan Tim Pengabdian Tematik Program Rumah Pangan Lestari dilaksanakan sejak bulan Januari 2021 hingga Februari 2021 di Lingkungan BTN RSS, Kelurahan Sekarteja, Kecamatan Selong, Kabupaten Lombok Timur. Pelaksanaan program kegiatan menggunakan vertikultur dan teknik vertical garden. Teknik vertical garden dapat diaplikasikan di berbagai bangunan (outdoor maupun indoor), pagar, carport, serta dinding-dinding pembatas lainnya, sehingga terlihat lebih indah dan tidak monoton berupa dinding yang keras, tapi lebih terkesan alami, bahkan dapat menyerupai lukisan yang sangat artistik (Sari, 2013). Teknik vertical garden juga dapat digunakan untuk menanam sayuran seperti kangkung, sawi pakcoy, sawi pagoda, selada merah dan selada hijau, cabai, bayam, tomat, dan terong. Selain itu dilakukan juga penanaman tanaman obat pada hari yang sama, adapun beberapa jenis tanaman obat yang ditanam yaitu serai, kunyit, jahe putih, jahe merah, lengkuas, temulawak, dan kencur. Setiap harinya tanaman disiram pada pagi dan sore hari. Teknik vertical garden ini memiliki kelebihan diantaranya (1) Menanam tanaman sehat. (2) Menciptakan pemandangan yang menarik. (3) Memaksimalkan lahan yang terbatas. (4) Menanam lebih banyak tanaman. (5) Meningkatkan kualitas udara dan Kesehatan. (6) Meningkatkan hasil tanaman.

Alat dan bahan serta prosedur yang digunakan untuk menanam dengan teknik vertical garden adalah gelas plastik, paku, lilin, besi, kawat, media tanam, dan benih. Prosedur: (1) Memotong botol plastik sesuai dengan bentuk yang diinginkan. (2) Melubangi botol plastik. (3) Mengecat botol plastik untuk mempercantik. (4) Mengisi tanah kemasing-masing botol. (5) Menanam bibit ke media tanam. (6) Pemasangan kawat pada botol plastik (7) Meletakkan masing-masing botol yang sudah dipasang paku. (8) Lakukan penyiraman dua kali sehari pagi dan sore hari dengan tetap memperhatikan kadar air untuk mencegah terjadinya pembusukan pada tanaman (9) Letakkan di tempat yang terkena sinar matahari langsung karena baik untuk pertumbuhan tanaman.

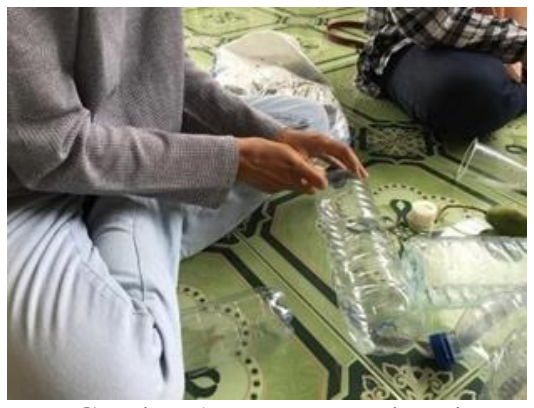

Gambar 1. Memotong botol

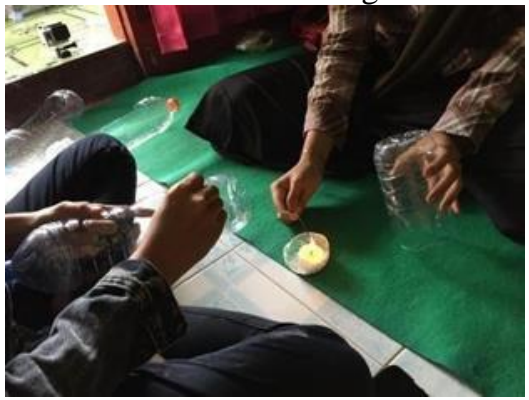

Gambar 2. Melubangi botol

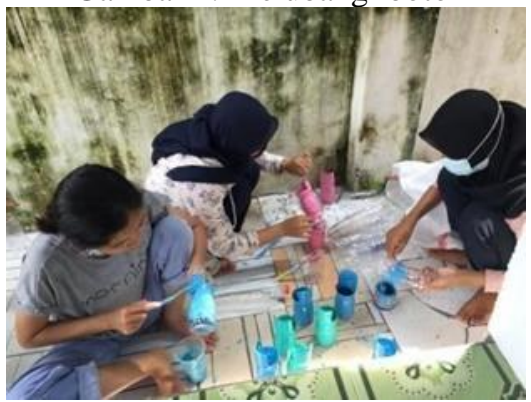

Gambar 3. Mengecat botol

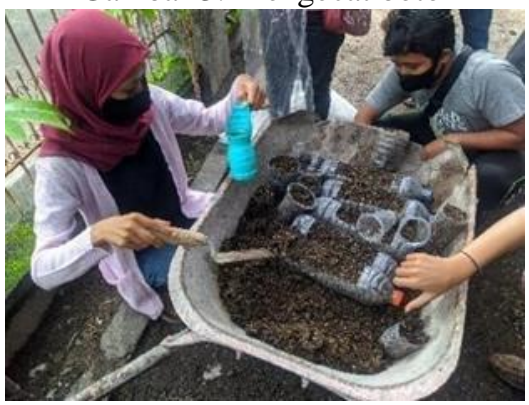

Gambar 4. Mengisi tanah pada botol 


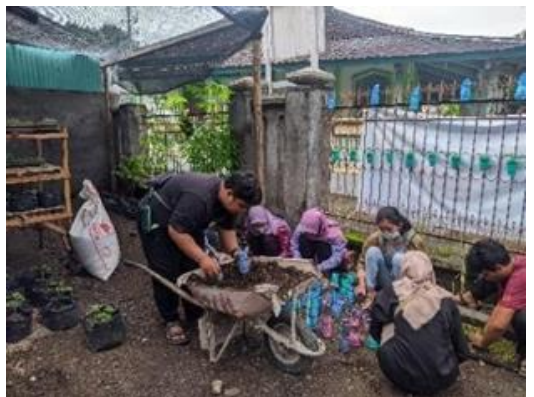

Gambar 5. Menanam bibit

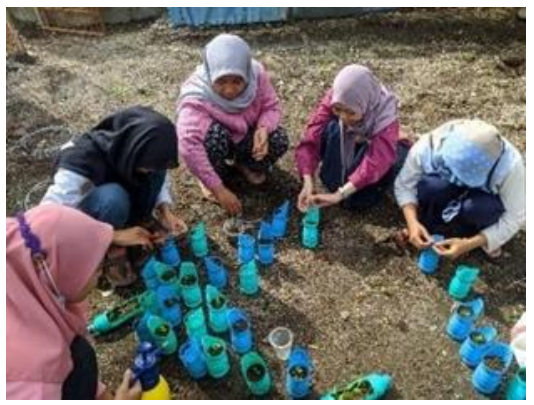

Gambar 6. Pemasangan kawat

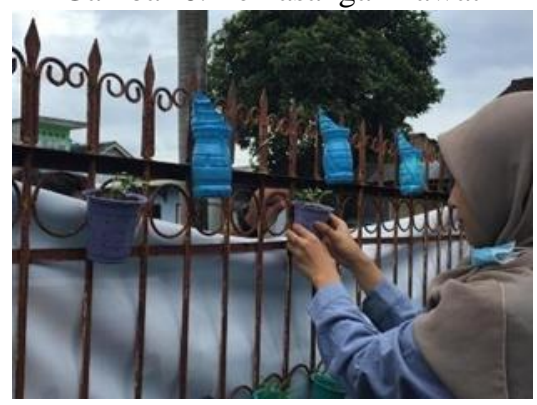

Gambar 7. Menggantung pot

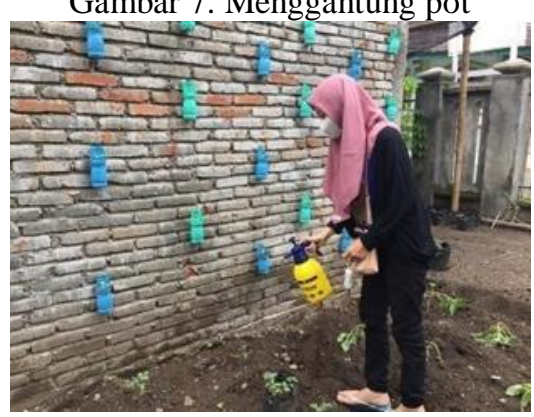

Gambar 8. Menyiram tanaman

Teknik vertikultur memungkinkan untuk berkebun dengan memanfaatkan tempat secara efisien. Bercocok tanam secara vertikultur sebenarnya sangat sederhana, tingkat kesulitannya tergantung dari model yang digunakan. Model yang sederhana mudah diikuti dan dipraktekan, bahkan bahan-bahan yang digunakan mudah ditemukan sehingga dapat diterapkan oleh kelompok. Jenisjenis tanaman yang ditanam biasanya adalah tanaman yang memiliki nilai ekonomi dan berumur pendek atau tanaman semusim khususnya sayuran seperti kangkung, selada, timun, bayam, singkong, terong, daun mint, pakcoy, kunyit, jahe, timun, singkong dan lengkuas. Teknik vertikultur ini memiliki beberapa kelebihan diantaranya (1) Efisiensi dalam penggunaan lahan. (2) Penghematan pemakaian pupuk dan pestisida. (3) Dapat dipindahkan dengan mudah karena tanaman diletakkan dalam wadah tertentu. (4) Mudah dalam hal monitoring/pemeliharaan tanaman. Membantu menghemat pengeluaran.

Alat dan bahan serta prosedur yang digunakan untuk menanam dengan teknik vertikultur adalah terai semai, polybag, gelas plastik, botol plastik, tanah, benih sayuran, dan air. Prosedur: (1) Siapkan terai semai (potray) yang sudah terisi media tanam berupa tanah yang sudah dicampur dengan pupuk dan sekam bakar lalu tebarkan benih diatasnya. (2) Lakukan penyiraman rutin dengan sprayer setiap pagi dan sore agar media selalu lembab. (3) Setelah benih berumur kurang lebih 10-14 hari, pindahkan benih yang sudah siap tanam tersebut ke polybag yang sudah berisi media tanam. (4) Lakukan pemeliharaan dengan menyiram tanaman setiap pagi dan sore hari. (5) Pilih tempat terbuka sehingga tanaman memperoleh sinar matahari yang cukup. (6) Lakukan penyiangan (kegiatan mencabut gulma yang berada di antara sela-sela tanaman) apabila ada rumput yang mengganggu dan mengecek setiap hari kondisi tanaman agar terhindar dari hama. (7) Setelah 25-28 hari, beberapa jenis tanaman sudah siap untuk dipanen.

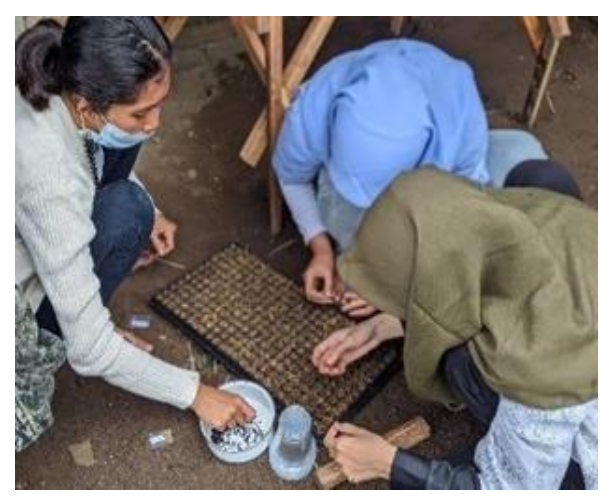

Gambar 9. Menanam benih pada potray 


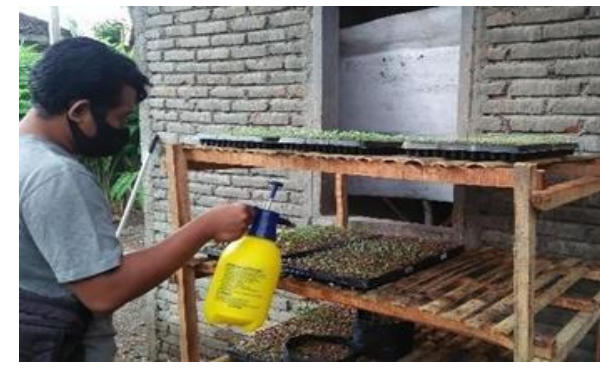

Gambar 10. Menyiram bibit

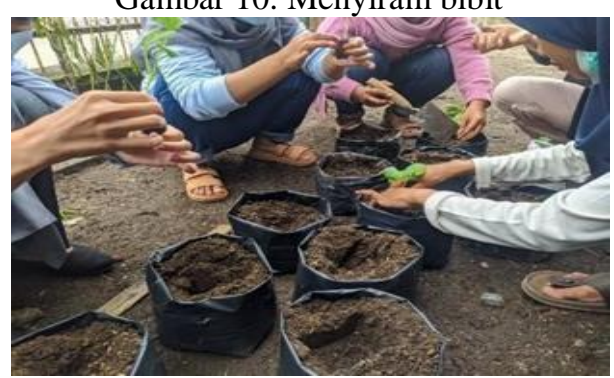

Gambar 11. Pemindahan benih pada media

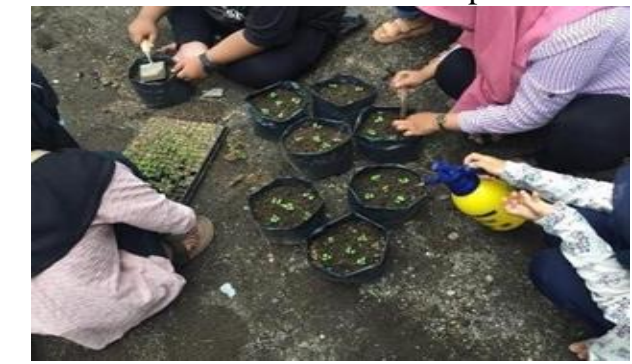

Gambar 12. Penanaman bibit pada media tanam tanam

Pembuatan bedengan sebagai media untuk pertumbuhan dan perkembangan tanaman. Istilah "bedengan" tersebut sama artinya dengan istilah "gulutan". Bedengan memiliki fungsi dan manfaat antara lain (1) Sebagai media tumbuh untuk penanaman berbagai macam jenis tanaman budidaya. (2) Untuk mencegah tanaman dari serangan hama dan juga penyakit. (3) Untuk menjaga kelembaban, $\mathrm{pH}$, suhu, dan juga ketercukupan air tanah, (4) Dapat membuat akar tanaman lebih kokoh dengan porsi bedengan yang serasi dengan ukuran morfologi tanaman. (5) Dapat mempermudah dalam irigasi lahan, karena pemanfaatan air akan efektif bagi tanaman, sehingga jika dilakukan dengan bijak dalam irigasi lahan, maka mencegah dari kebusukan akar ketika tanaman mendapat pasokan air irigasi yang berlebihan. (6) Sebagai nilai estetika (keindahan), supaya tanaman tumbuh secara tertib, teratur, sesuai garis alur bedengan masing-masing. (7) Mempermudah dalam pemantauan tanaman, dalam hal perawatan, termasuk dalam hal penyiraman, penyiangan, dan juga proses pemanenan tanaman.

Alat dan bahan serta prosedur yang digunakan untuk membuat bedengan tanaman sayuran adalah cangkul. Prosedur: (1) Siapkan alat dan bahan. (2) Buang rumput yang berada di lahan yang akan dibuat bedengan. (3) Cangkuli tanah dan buatlah bedengan. (4) Pembuatan bedengan telah selesai dan siap ditanami.
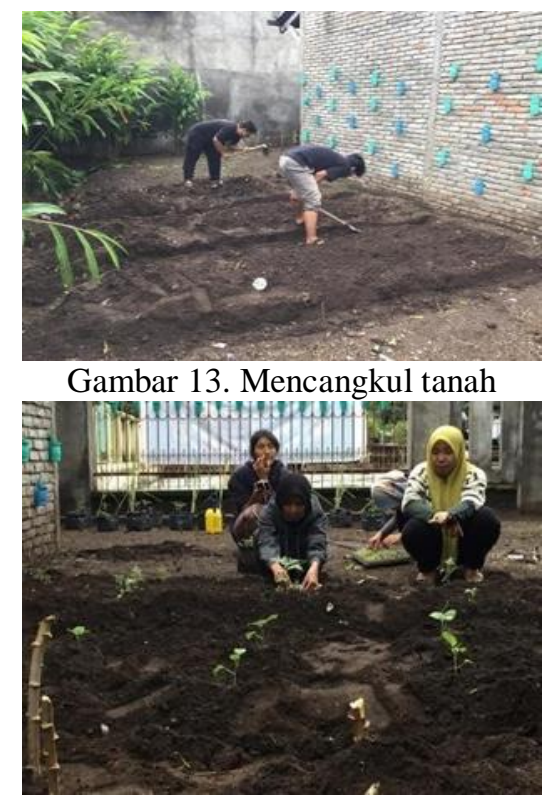

Gambar 14. Menanam di bedengan

Sosialisasi mengenai pembuatan lubang biopori atau lubang resapan sekaligus pembagian bibit pada masyarakat. Lubang resapan biopori adalah lubang silindris yang dibuat secara vertikal ke dalam tanah sebagai metode resapan air yang ditujukan untuk mengatasi genangan air dengan cara meningkatkan daya resap air pada tanah. Kedalaman biopori mencapai $50-100 \mathrm{~cm}$. Manfaat dari biopori, yaitu memperluas bidang penyerapan air, sebagai penanganan limbah organik, dan meningkatkan kesehatan tanah. Selain itu, biopori juga bermanfaat secara arsitektur lanskap sehingga telah digunakan sebagai pelengkap pertamanan di berbagai rumah mewah dan rumah minimalis yang menerapkan konsep rumah hijau.

Alat dan bahan serta prosedur yang digunakan untuk membuat lubang biopori adalah cepang, linggis, dan pipa paralon. Prosedur: (1) Tentukan lokasi tanah yang akan dijadikan lubang biopori. (2) Siram tanah agar menjadi lunak dan mudah dilubangi. (3) Lubangi tanah dengan bor 
biopori atau bor tanah dan buat secara tegak lurus. (4) Buat lubang sedalam 1 meter dengan diameter 10-30 cm. (5) Lapisi lubang dengan pipa pralon seukuran diameter lubang yang sudah disiapkan. (6) Isi lubang dengan sampah organik seperti daun, rumput, dan lain-lain. (7) Tutup lubang dengan kawat besi atau tutup pipa paralon yang sudah dilubangi.

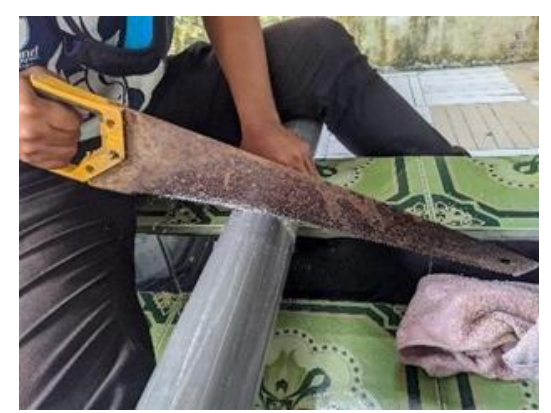

Gambar 15. Memotong pipa

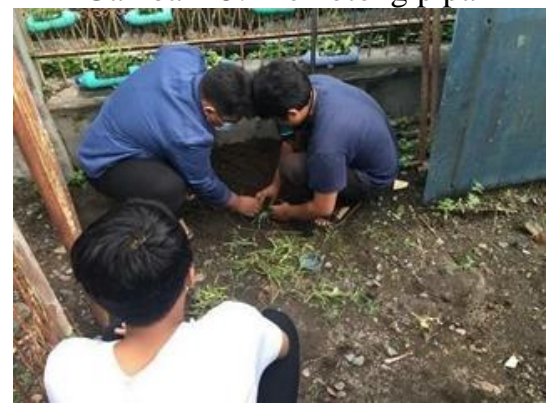

Gambar 16. Memasukan pipa

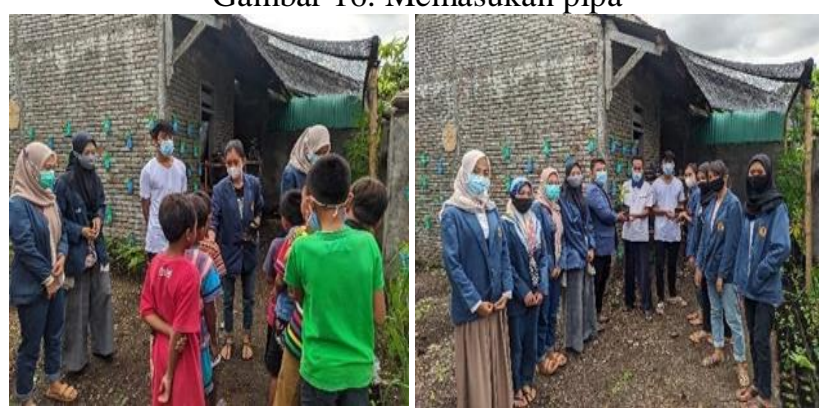

Gambar 17. Sosialisasi sekaligus pembagian bibit dan penyerahan lahan KRPL pada masyarakat BTN RSS

Tujuan dari kegiatan ini sangat penting bagi masyarakat dalam memenuhi kebutuhan pangan khususnya sayur-sayuran di skala rumah tangga dan hasilnya bisa di jual kembali. Setelah adanya kegiatan ini masyarakat dapat menerapkan dan memanfaatkan lahan pekarangan yang sempit di kediamannya masing-masing sehingga dapat memenuhi kebutuhan sayur-sayuran yang sehat untuk keluarga dengan budidaya tanaman vertikultur dan vertical garden yang bisa bermanfaat di kemudian hari.

\section{Kesimpulan}

Berdasarkan hasil kegiatan dan berbagai program kerja yang telah dilaksanakan melalui kegiatan Tim Pengabdian ini dapat ditarik kesimpulan bahwa Pemanfaatan Pekarangan Rumah Sebagai Kawasan Rumah Pangan Lestari (KRPL) di Lingkungan BTN RSS dapat dikatakan memberikan manfaat yang besar bagi masyarakat setempat, sehingga masyarakat setempat mulai terbangun untuk mewujudkan Rumah Pangan Lestari yang lebih baik lagi untuk kedepannya. Kendala dari kegiatan ini adalah adanya beberapa bibit tanaman yang tidak tumbuh ataupun tumbuh nsmun mengalami kekerdilan aibat dari cuaca yang tidak menentu. Selain itu, adanya pandemic covid19 sehingga kegiatan sosialisasi tidak terealisasi dengan baik dan hanya seadanya.

\section{Ucapan Terima Kasih}

Ucapan Terima kasih disampaikan kepada Bapak Lurah Kelurahan Sekarteja, Kecamatan Selong, Kepala Lingkungan BTN RSS, Ketua PKK, serta masyarakat Lingkungan BTN RSS yang telah mendukung dan memfasilitasi kegiatan Mahasiswa Tim Pengabdian Tematik Universitas Mataram Tahun 2020/2021 di Kelurahan Sekarteja, Kecamatan Selong.

\section{Daftar Pustaka}

Desiliyarni, I. T., Msi, D., Astuti, Y., dan Fauzy, I. F. (2003). Vertikultur; Teknik Bertanam di Lahan Sempit. Agro Media. Denpasar.

Sari, F.M, 2013. Perancangan Vertical Garden Untuk Kantor PLN AJP Surakarta (DP3A). Skripsi. aUniversitas Muhammadiyah Surakarta.

Sihombing, Y. A. Susilawati, M. Z. Sinaga, 2019. Introduction of verticulture technique for utilization of spring land in Madrasah Tsanawiyah (MTs) ibnu sina City of Pematang Siantar. Abdimas Talenta. 4 (1): 872-876. 